\title{
Article
}

\section{Towards AquaSun practical utilization: strong adhesion and lack of ecotoxicity of solar-driven antifouling sol-gel coating}

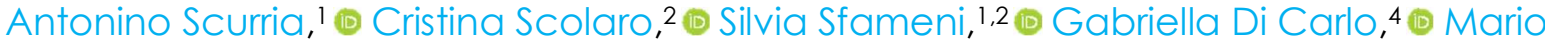

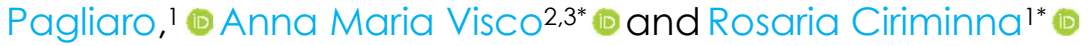

'Istituto per lo Studio dei Materiali Nanostrutturati, CNR, via U. La Malfa 153, 90146 Palermo (Italy)

2Dipartimento di Ingegneria, Università di Messina, Contrada di Dio, Villagio S. Agata, 98166 Messina (Italy) 3stituto per i Polimeri, Compositi e Biomateriali, CNR, via P. Gaifami 18, 9-95126 Catania, Italy

${ }^{4}$ Istituto per lo Studio dei Materiali Nanostrutturati, CNR, via Salaria km 29.3, 00015 Monterotondo RM (Italy)

*Correspondence: rosaria.ciriminna@cnr.it and annamaria.visco@unime.it

\section{SUMMARY}

The outcomes of adhesion and ecotoxicity tests carried out on metal specimens faithfully representing the surface of real ships, including the primer and tie coat layers typically applied on ship hull prior to deposition of the antifouling paint, show the practical applicability of "AquaSun" antifouling sol-gel coatings. Newly developed AquaSun coatings share superhydrophicity (contact angle $>115^{\circ}$ ) and exceptionally high scratch resistance (ASTM 5B). Coupled to the ecofriendly antifouling mechanism based on continuous $\mathrm{H}_{2} \mathrm{O}_{2}$ formation upon exposure to solar light and foul release due to low surface energy, these results open the route to the practical utilization of these novel marine coatings.

Keywords: AquaSun; antifouling; ecofriendly; sol-gel; coating

\section{INTRODUCTION}

Protection of ships and boats from marine and lake biofouling applying on the hull an antifouling (AF) paint is an unavoidable necessity. A ship without protection after 6 months will consume $40 \%$ more "bunker" fuel oil (and engine power output) due to additional dragging and friction originating from the surface roughness of macro- and microorganisms foulant organisms accumulating on the unprotected hull. ${ }^{[1]}$ Following the global ban of highly toxic tributyltin-based paints, the most commonly used AF coatings today are based on the biocidal action of copper oxide $\left(\mathrm{Cu}_{2} \mathrm{O}\right)$ and copper thiocyanate (CUSCN) typically formulated at 20-40 per cent concentrations in combination with "booster" biocides, such as copper or zinc pyrithione, and other synthetic antifungal, herbicide, and pesticide synthetic molecules originating from crop protection research in agriculture. ${ }^{[2]}$ The amount of AF paints globally consumed by the world's fleet grows at $10 \%$ annual rate. ${ }^{\left[{ }^{[3]}\right.}$ Hence, the $>80,000$ tonne annual consumption estimated by an industry's practitioner in 2010, ${ }^{[4]}$ now largely exceeds the 100,000 tonne threshold. One such paint is designed to last 3-5 years, gradually releasing all the incorporated biocides, causing a significant (and global) impact on marine life. ${ }^{[5]}$

For example, a recent study on copper-based paints in the Venice lagoon revealed that copper leached by these paints has potential disruptive effects on the biodiversity of coastal macrofouling communities affecting both the settlement and growth of key species of macrofouling of hard-substrata. ${ }^{[6]}$ 
Based either on less toxic biocides, or on foul-release (FR) polymeric coatings, in the last two decades (2000-2020) new environmentally benign antifouling paints have been commercialized. ${ }^{[7,8]}$ Amid them, the waterborne xerogel thin coatings made of organically modified silica (ORMOSIL) developed by Detty and Bright in the early $2000 \mathrm{~s}^{\left[{ }^{\left[{ }^{0}\right.}\right.}$ were first commercialized (with the AquaFast tradename) in the early 2010s. ${ }^{[10]}$ Their efficacy relies on the FR activity imparted to the hull by the thin hydrophobic ORMOSIL layer. ${ }^{[1]}$ Biofoulants sticking loosely to the hull are released even at low cruising speed. Unfortunately, these ecofriendly, biocide-free coatings do not exert antifouling action when the vessel stands still, for example in port waters.

Named AquaSun, an ORMOSIL-based coating showing excellent AF activity due to solardriven photocatalytic generation of $\mathrm{H}_{2} \mathrm{O}_{2}$ and hydroxyl radicals, is comprised of thin film (3 $\mu \mathrm{m}$ thick) of methylated silica sol-gel derived from a sol containing $50 \mathrm{~mol} \%$ methyltriethoxysilane (MTES) and $50 \mathrm{~mol} \%$ of tetraethyl orthosilicate (TEOS) encapsulating in flower-like microparticles of the visible-light photocatalyst $\mathrm{Bi}_{2} \mathrm{WO}_{6} \cdot{ }^{[12]}$ As shown by investigation of the antifouling effect of hydrogen peroxide release from enzymatic marine coatings, ${ }^{[13]} \mathrm{H}_{2} \mathrm{O}_{2}$ degrades the adsorbed species forming hydroxyl radicals $(\mathrm{HO} \bullet)^{[144]}$

Tested under real life situations irradiating with (simulated) solar light for over 3 months a substrate coated with AquaSun immersed in the waters of Indian Ocean, the coating retained its excellent original AF activity. ${ }^{\left[{ }^{[15]}\right.}$ Remarkably, indicating no saturation effects, the activity degradation rate was found to be linear with about half of 1 ppm of added uracil being degraded in three days. ${ }^{[12]}$ Under solar light, marine phytoplankton microorganisms consuming inorganic carbon give place to photosynthesis providing organic matter for the organisms that comprise the majority of marine life. ${ }^{[16]}$ The same coating also shares good FR properties, as shown by full release in water in $2 \mathrm{~h}$ only of all the adenine adsorbed from a 1 ppm solution, even in the absence of light irradiation. Given the high stability, low cost, and environmentally benign nature of silica-based sol-gel coatings, the study concluded that "technology has significant potential toward replacing conventional antifouling and foul-release coatings with a single product of broad applicability". ${ }^{[15]}$ On path to demonstrate the practical applicability of this new marine AF/FR coating, now we report the outcomes of adhesion experiments on real ship steel substrates as well as the first ecotoxicity experiments.

\section{EXPERIMENTAL METHODS}

2.1 Preparation of the xerogel films and topcoat deposition

All chemicals were purchased by Sigma-Aldrich (now Merck, Milano, Italy) and used as such, without further purification. C18 stands for $n$-octadecyltrimethoxysilane. C8 stands for $n$-octyltriethoxysilane. The AquaSun xerogel film was prepared starting from a formulation incorporating $12 \% \mathrm{w} / \mathrm{w}$ of $\mathrm{Bi}_{2} \mathrm{WO}_{6}$ (with respect to the theoretical weight of silica) suspended in the $\mathrm{C}_{18} 1 \% / \mathrm{C} 849 \% / \mathrm{TEOS}_{50} \%$ silicon alkoxide solution in 2-propanol through hydrolytic polycondensation under acidic conditions $(\mathrm{HCl} 0.1 \mathrm{~N})$. In detail, a $10 \mathrm{~mL}$ flask was added under vigorous stirring with TEOS ( $4 \mathrm{mmol}, 0.89 \mathrm{~mL}), \mathrm{C} 8(3.92 \mathrm{mmol}, 1.30$ $\mathrm{mL}), \mathrm{C}_{18}(0.08 \mathrm{mmol}, 40 \mu \mathrm{L})$, 2-propanol $(2.6 \mathrm{~mL})$ and $\mathrm{HCl} 0.1 \mathrm{M}(0.5 \mathrm{~mL})$. The resulting solution was left under stirring for $24 \mathrm{~h}$ after which an aliquot of $\mathrm{Bi}_{2} \mathrm{WO}_{6}(55.8 \mathrm{mg}, 12 \% \mathrm{w} / \mathrm{w})$ was added under stirring. The resulting xerogel film was named THA8. A blank film devoid of bismuth wolframate was also prepared and named THA8B. These coatings were deposited on pre-treated real ship steel substrates by simple coating the pre-treated surface with a brush. In detail, the metal plate was pretreated with the Tie Coat paint (Jotun, Sandefjord, Norway). The latter paint was prepared by mixing three different components: component A (40 g, Safeguard Universal ES Comp A), component B (8 g, Safeguard Universal ES Comp B) and finally the solvent ( $5 \mathrm{~g}$, Jotun Thinner No. 17). The Tie Coat was deposited using a roll while THA8 and THA8B were deposited with a paintbrush. The aforementioned and related sol-gel coatings functionalized with $\mathrm{Bi}_{2} \mathrm{WO}_{6}$ were coated on glassy substrates for scanning electron microscopy investigation. Prior to deposition of the xerogel film via spin coating each glass was cleaned by leaving it in contact with a concentrated $(1 \mathrm{M}) \mathrm{HCl}$ aqueous solution for $24 \mathrm{~h}$, followed by extensive washing with triple distilled water and ethanol and drying in open air. 
2.2 SEM imaging and energy-dispersive spectroscopy

The coating surface investigation and dopant particle morphology were analyzed a high brilliance Zeiss LEO 1530 field emission scanning electron microscope (FE-SEM; Carl Zeiss, Oberkochen, Germany) apparatus equipped with an energy dispersive X-ray spectrometer (EDS) INCA 450 (Oxford Instruments, Abingdon, Great Britain) and a four sector backscattered electron (BSE) and secondary electron (SE) detectors. FE-SEM investigations were performed by using both SE and BSE electrons and selecting an acceleration voltage of $20 \mathrm{kV}$.

2.3 Surface roughness, contact angle, adhesion test and viscosity experiments

The surface roughness $\left(R_{\mathrm{a}}\right)$ of the xerogel films was measured with a Surftest SJ-210 Series 178 surface roughness tester (Mitutoyo, Milan, Italy) using equation 1 , in which $R_{\mathrm{a}}$ is calculated as the arithmetic mean of the absolute values of the deviations of the evaluation profile $(Y i)$ from the mean line.:

$$
R_{a}=\frac{1}{N} \sum_{i=1}^{n}|Y i|
$$

The contact angle $\theta$ was assessed by the sessile drop method by means of a prototype instrument at the Engineering Department of Messina University, which measures the contact angle of $1 \mu \mathrm{L}$ drop of deionized water of on the horizontal surface of the film. The wet ability was derived from equations 2 and 3 :

$$
\theta_{w}=2 \operatorname{arctg}\left(\frac{2 h}{d}\right) \quad(2) ; \theta_{Y}=\operatorname{arcos}\left(\frac{\cos \theta_{w}}{r}\right)
$$

where $d$ is the diameter and $h$ the height (both in $\mathrm{mm}$ ) of the drop, $\theta_{\mathrm{w}}$ is the Wenzel angle apparent dependent on the roughness of the surface, $r$ is the surface roughness $\left(R_{\mathrm{a}}\right)$, and $\theta_{r}$ is the Young contact angle of equilibrium on a perfectly smooth surface.

The adhesion of coating films to metallic substrate was evaluated by cross-cut test using a commercial Cross Hatch Adhesion Tester (Sama Tools - SADT502-5) according to ASTM D3359e2 Standard Test Method for Measuring Adhesion by Tape Test. Using an appropriate cutter, a grid incision was made in a test area of approximately $10 \times 10 \mathrm{~cm}$, creating a grid of horizontally and vertically spaced $(2 \mathrm{~mm}$ ) spaced $(2 \mathrm{~mm}$ ) horizontally and vertically spaced incisions across the surface. All the particles produced in the area were then removed with a soft brush. As a rule, a $3 \mathrm{M}$ adhesive tape is stuck onto the cutting grid with a finger, applying a light pressure. It is subsequently removed with an even peeling movement. The test is evaluated visually by comparing the sectional grid image with the reference images from ISO 2409:2013. Depending on the condition of the damage, a crosscut parameter from o (very good adhesive strength) to 5 (very poor adhesive strength) is assigned according to the number of squares that have flaked off and the appearance.

The flow behavior of liquid-like samples at room temperature was analyzed through a rotational rheometer ( $\mathrm{MC}-502$, Anton Paar, Graz, Austria) consisting of a rotating rod immersed in the liquid to be analyzed. The terminal part of the rod has a specific shape (geometry). Measurements for this work were carried out by using the cone-plate geometry. For each geometry the lower support was always fixed (only the upper part is connected to the motor moves). Each viscosity test was performed at room temperature of $25^{\circ} \mathrm{C}$ within the shear rate from $0.01 \mathrm{~s}^{-1}$ up to $1000 \mathrm{~s}^{-1}$. Each test was carried out three times. The linear viscoelasticity region (LVR) was checked by an amplitude sweep test of both the topcoats THA8 and THA8B at a constant frequency of $1 \mathrm{~Hz}$.

\subsection{Microtox test}

The Microtox toxicity tests were carried out according to the standard procedures described in EN12457, using standardized (ISO) seawater at $100 \mathrm{mg} / \mathrm{L}$ starting concentration.

\section{RESULTS AND DISCUSSION}

In 2011, Detty, Bright and co-workers reported that the original AquaFast formulation (1:1 C8/TEOS) could be substantially improved with respect to the foul release of juvenile 
barnacles and sporeling biomass by simply adding a 1 per cent (in molar terms) of C 18 ( $n$ octadecyltrimethoxysilane) to the sol-gel formulation. ${ }^{\left[{ }^{17]}\right.}$ Expanding on these previous findings we prepared a AquaSun xerogel film starting from the same formulation incorporating $\mathrm{Bi}_{2} \mathrm{WO}_{6}$ suspended in the pre-hydrolyzed $\mathrm{C}_{18} / \mathrm{C} 8 / \mathrm{TEOS} \mathrm{Si}$ alkoxide solution in aqueous propanol. The resulting xerogel film was named THA8B. A blank film devoid of bismuth wolframate (THA8) was also prepared. Figure 1 shows real ship steel substrates pre-treated with primer and tie coat further coated with a thin layer of these sol-gel coatings deposited by simple brushing with a paintbrush.
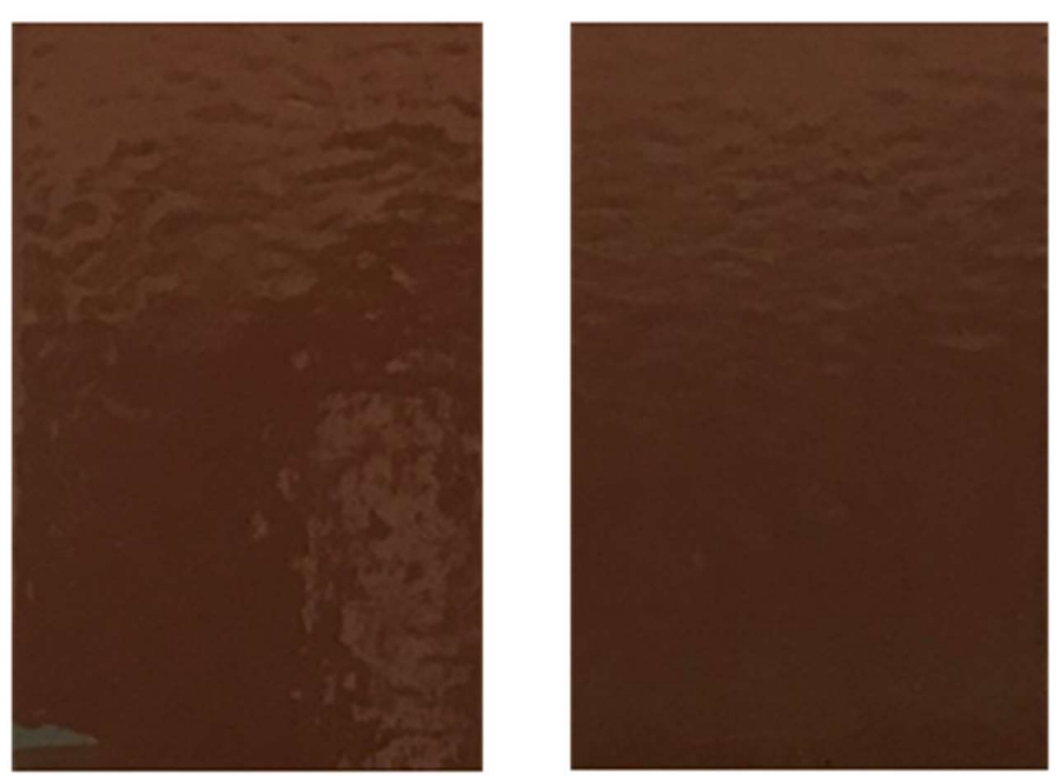

Figure 1. Metal plate with primer and tie coat coated with THA8 (left) and with THA8B (right)

The ability of ORMOSIL sol-gel coatings to modify the contact angle and the roughness of the coated surface was proven in a broad interval of ORMOSIL xerogel film compositions, using three different alkyl-modified $\mathrm{Si}$ alkoxides of different alkyl length $\left(\mathrm{C}_{1}, \mathrm{C}_{3}\right.$, and $\mathrm{C}_{18}$; for the xerogel composition, see Table 3). Figure 2 further shows the metal substrate with the tie coat only, and the same substrate following application of THA 8. Clearly the coating is homogeneously deposited. The SEM images show the homogeneous nature of the few $\mu \mathrm{m}$ thick xerogel films deposited on glass also on the submicron scale, along with the concomitant presence of flower-like $\mathrm{Bi}_{2} \mathrm{WO}_{6}$ crystallites (Figure 2). 

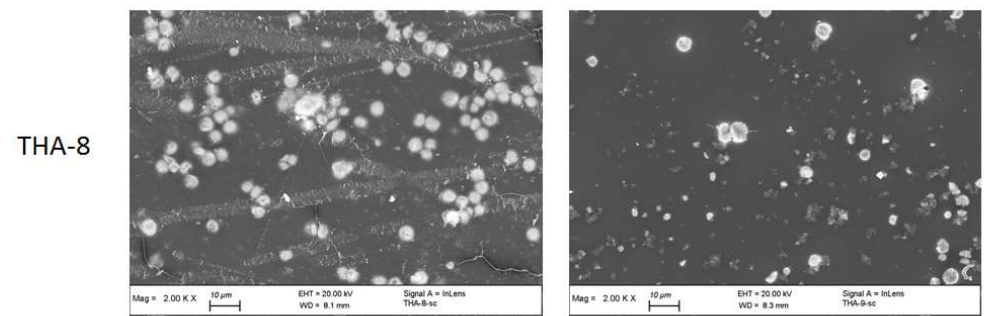

THA-9
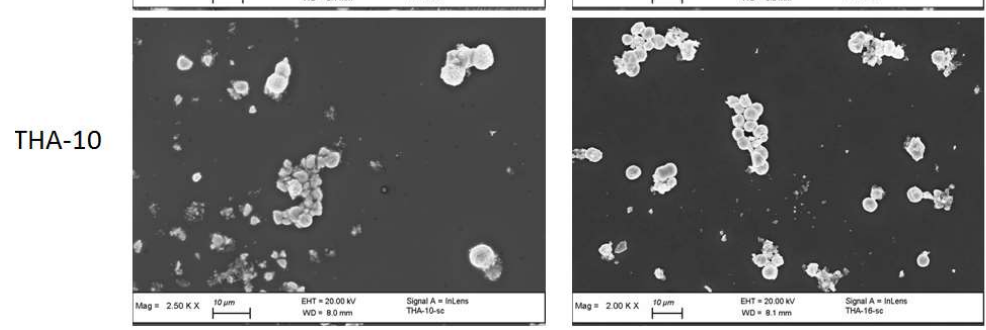

THA-16

Figure 2. FSE-SEM photographs of different AquaSun xerogel films deposited on glass (for xerogel composition, see Table 3)

The successful encapsulation of the flower-like $\mathrm{Bi}_{2} \mathrm{WO}_{6}$ microparticles in the xerogel matrix was clearly shown by the FSE-SEM analysis at large magnification $(\times 23,000)$ coupled to the EDS spectra (Figure 3). The elemental composition of the microparticle returned by electron diffraction confirms the presence of $\mathrm{Bi}, \mathrm{W}, \mathrm{O}, \mathrm{Si}$ and $\mathrm{C}$ typical of the ORMOSILentrapped bismuth wolframate xerogel, whereas film regions free of dopant species were also clearly detected by the FSE-SEM and EDS analyses (Figures 2 and 3 ).

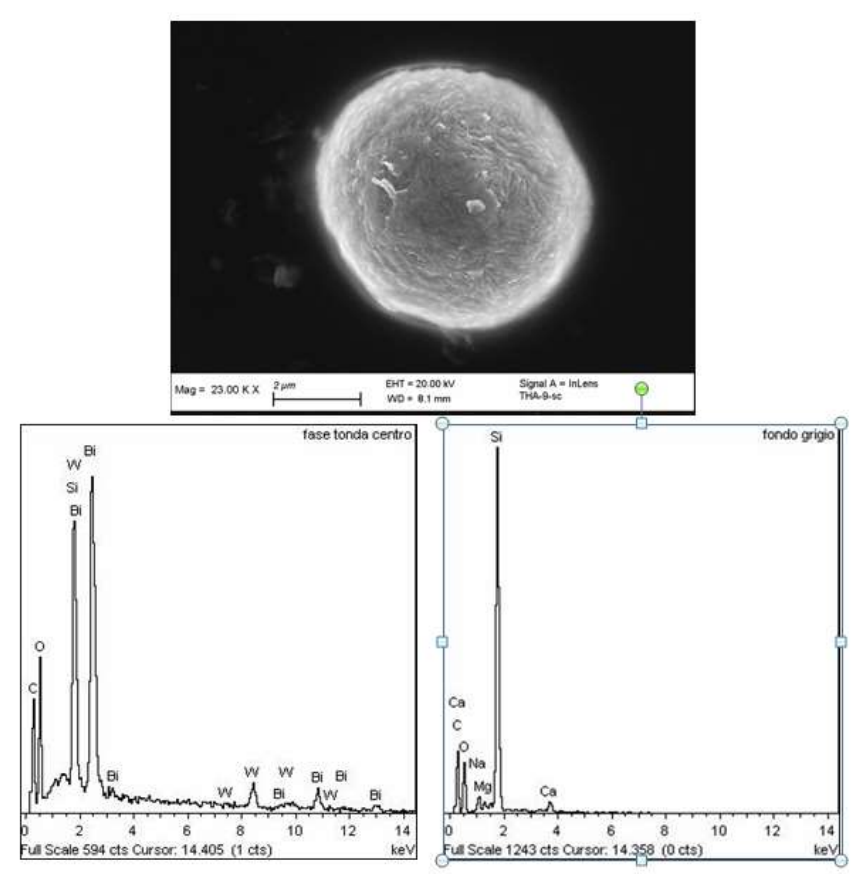

Figure 3. FSE-SEM image of a flower-like $\mathrm{Bi}_{2} \mathrm{WO}_{6}$ microparticle encapsulated in the THA-9 sc AquaSun xerogel (for xerogel composition, see Table 3 ) deposited on glass (top). EDS spectra of the encapsulated microparticle (bottom left) and embedding organosilica matrix (bottom right). 
Evidence of excellent adhesion of both THA 8 and THA 8B xerogel films on the steel substrates was obtained by characterization of the coatings in terms of adhesion strenght, thickness and contact angle (Table 1).

Table 1. Thickness $(T)$, roughness $\left(R_{\mathrm{a}}\right)$, Wenzel $\left(\theta_{\mathrm{W}}\right)$ and Young $\left(\theta_{\mathrm{Y}}\right)$ contact angles of different substrates

\begin{tabular}{lcccc}
\hline Substrate & $T(\mu \mathrm{m})$ & $R_{\mathrm{a}}(\mu \mathrm{m})$ & $\vartheta_{\mathrm{w}}\left(^{\circ}\right)$ & $\vartheta_{\mathrm{Y}}(\% / \mu \mathrm{m})$ \\
\hline Steel PRIMER + TIE COAT & 568 & 6.76 & $81.8 \pm 2.9$ & $88.8 \pm 2,9$ \\
\hline Steel P+T+ THA8 & 216 & 2.13 & $94.1 \pm 1.1$ & $91.9 \pm 1.1$ \\
\hline Steel P+T+ THA8B & 113 & 9.31 & $95.5 \pm 1.2$ & $90.6 \pm 1.2$ \\
\hline
\end{tabular}

$\mathrm{P}=$ primer $; \mathrm{T}=$ tie coat

Data in Table 1 and Figure 4 show that coating the corrosion-protected steel substrate with both THA8 and THA8B organosilica coatings impart high contact angle values, confirming the ability of these ORMOSIL-based coatings to impart high hydrophocity to the coated surface ${ }^{[18]}$ Figure 4 shows that the Wenzel and Young contact angle values of the commercial tie-coat, significantly increase after deposition of the THA8 "AquaSun" and THA8B blank ORMOSIL topcoats. The presence of the entrapped $\mathrm{Bi}_{2} \mathrm{WO}_{6}$ in the THA8 coating results in a slightly lower Wenzel angle, but slightly larger Young angle when compared to the blank topcoat.

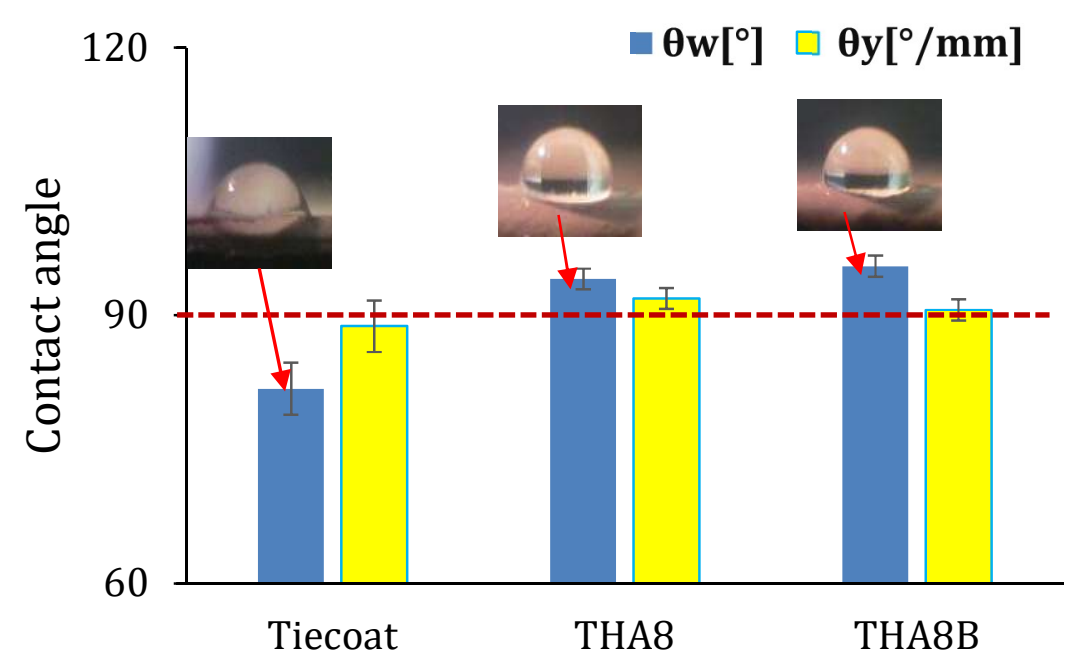

Figure 4. Wenzel and Young contact angle values of commercial tie coat, and of THA8 and THA8B topcoats.

The cross-cut adhesion test gives a visual comparison method of testing coating adhesion integrity assessed against ISO 2409 and ASTM D 3359 standards, returned the maximum adhesion values for both substrates, namely ISO o and ASTM ${ }_{5} \mathrm{~B}$. We briefly remind that a coating is assigned the ASTM ${ }_{5} \mathrm{~B}$ value when the edges of the cuts are completely smooth and none of the squares of the lattice formed upon the cuts is detached. ${ }^{[19]}$ From the utilization viewpoint, as put it by Valli discussing thin hard coatings to protect steel, adhesion is the most important property of a coating. ${ }^{[20]}$ 


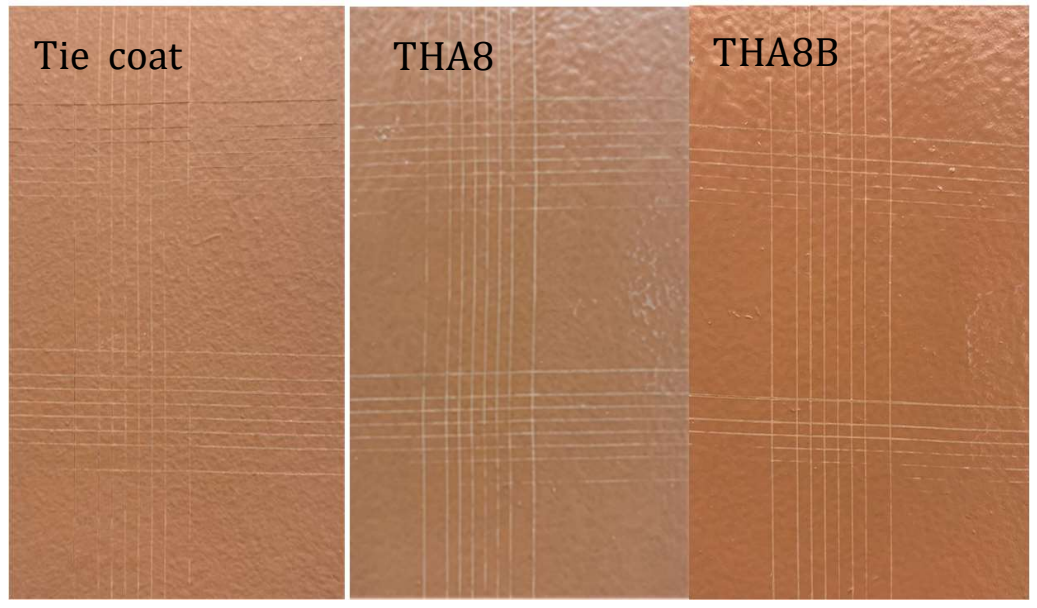

Figure 5. Adhesion-cross cut test of commercial tie coat, THA8 and THA8B topcoats.

The edges of the cuts shown in Figure 5 are completely flat, none of the squares of the lattice are detached, in accordance with the reference standards. This uniquely high scratch resistance proves the excellent adhesion levels of these coatings previously obtainable only with physical vapor deposition and chemical vapor deposition techniques. ${ }^{[20]}$

To investigate the ecotoxicity of the AquaSun xerogel films obtained from TEOS and MTES according to the original material preparation route, we carried out the first acute toxicity tests with Vibrio fischeri (an in vitro test using the bioluminescent bacteria Aliivibrio fischeri to detect toxic substances in different environments) according to the published procedure for carrying out the Microtox test. ${ }^{[21]}$ Results in Table 2 show evidence of the complete absence of ecotoxicity.

Table 2. Ecotoxicity tests of AquaSun coatings with Vibrio fischeri (MicroTOX test)

\begin{tabular}{lcccc}
\hline Material & $\begin{array}{c}\mathrm{EC}_{50} \mathrm{mg} / \mathrm{L} \\
(15 \mathrm{~min})\end{array}$ & $\begin{array}{c}\mathrm{EC}_{50} \\
\mathrm{mg} / \mathrm{L}(30 \\
\mathrm{min})\end{array}$ & $\begin{array}{c}\% \text { Effect } \\
100 \mathrm{mg} / \mathrm{L} \\
\text { sample }(15 \\
\mathrm{min})\end{array}$ & $\begin{array}{c}\text { \% Effect 100 } \\
\mathrm{mg} / \mathrm{L} \mathrm{sample} \\
(30 \mathrm{~min})\end{array}$ \\
\hline THA 6 & $\mathrm{NL}^{\mathrm{a}}$ & $\mathrm{NL}$ & $\mathrm{NL}$ & - \\
\hline THA 6B & $\mathrm{NL}$ & $\mathrm{NL}$ & $\mathrm{NL}$ & - \\
\hline THA 5 & $\mathrm{NL}$ & $\mathrm{NL}$ & $\mathrm{NL}$ & - \\
\hline THA 5B & $\mathrm{NL}$ & $\mathrm{NL}$ & $\mathrm{NL}$ & - \\
\hline
\end{tabular}

${ }^{a} \mathrm{NL}=$ within law limits

Further biological tests on the growth of different marine bacteria (Pseudoaltermonas, Alteromonas and Pseudomonas) in the presence of doped and non-doped (blank) AquaSun methylated xerogel films (not shown) fully confirmed that the antifouling activity is due to the photocatalytic action of the AquaSun coatings driven by solar light. Growth of bacteria in the films functionalized with flower-like was inhibited though the only solar light hitting the coatings was diffuse solar light such as that present in the laboratory where the experiments were conducted. 
Inhibition of bacterial population development was especially observed for the $50 \%$ methylmodified film THA 6 whose composition is the same of the optimal AquaSun xerogel coating in our original study, whereas this was not the case for the non-doped (blank) xerogel coatings. We remind here that the photocatalytic reaction on the submarine surface is triggered by visible-light radiation easily penetrates sea water, with reflection at moderate depths accounting to only 5-10\%, while absorption is negligible. ${ }^{[22]}$

When the film is applied on a surface constantly exposed to solar radiation, it continuously produces $\mathrm{H}_{2} \mathrm{O}_{2}$ according to Equations $4-8$, in which $V B$ and $C B$ stand, respectively, for valence and conduction band: ${ }^{[2]}$

$$
\begin{aligned}
& \mathrm{Bi}_{2} \mathrm{WO}_{6}+\mathrm{hv} \rightarrow \mathrm{Bi}_{2} \mathrm{WO}_{6}\left(\mathrm{e}^{-}{ }_{(\mathrm{CB})}+\mathrm{h}^{+}(\mathrm{VB})\right. \\
& \mathrm{OH}^{-}+\mathrm{h}^{+}(\mathrm{VB}) \rightarrow \cdot \mathrm{OH} \\
& \mathrm{O}_{2}+\mathrm{e}^{-}{ }_{(\mathrm{CB})} \rightarrow \mathrm{O}_{2} \cdot- \\
& \mathrm{O}_{2}^{\cdot-}+\mathrm{H}^{+} \rightarrow \mathrm{HO}_{2}^{\cdot} \\
& 2 \mathrm{HO}_{2}^{\cdot} \rightarrow \mathrm{O}_{2}+\mathrm{H}_{2} \mathrm{O}_{2}
\end{aligned}
$$

The ability of ORMOSIL sol-gel coatings to modify the contact angle and the roughness of the coated surface was proven in a broad interval of ORMOSIL xerogel film compositions, using three different alkyl-modified Si alkoxides of different alkyl length $\left(C_{1}, C_{3}\right.$, and $C_{1} 8$ ). Results in Table 3 indeed show that the xerogel films obtained with a small amount $(1 \mathrm{~mol}$ $\%$ ) of C8 alkyl groups have large surface roughness (THA 8B), but that said enhanced roughness is lost when encapsulating the photoactive species $\mathrm{Bi}_{2} \mathrm{WO}_{6}$ (THA 8). The contact

\begin{tabular}{|c|c|c|c|c|c|c|}
\hline Material & $\begin{array}{l}\text { Organic } \\
\text { group }\end{array}$ & $\begin{array}{c}\text { Degree of } \\
\text { functionalization } \\
(\%)\end{array}$ & $\begin{array}{c}\mathbf{B i}_{2} \mathbf{W O}_{6} \\
(\mathrm{mM})\end{array}$ & $\begin{array}{c}\boldsymbol{R}_{\mathrm{a}} \\
{[\mu \mathrm{m}]}\end{array}$ & $\vartheta_{w}\left[^{\circ}\right]$ & $\vartheta_{\mathrm{Y}}[\% / \mu \mathrm{m}]$ \\
\hline THA 5 B & $-\mathrm{CH}_{3}$ & 10 & - & 0.05 & 95.48 & 146.77 \\
\hline THA 5 & $-\mathrm{CH}_{3}$ & 10 & 50 & 0.15 & 92.54 & 130.82 \\
\hline THA 6 B & $-\mathrm{CH}_{3}$ & 50 & - & 0.56 & 91.35 & 95.48 \\
\hline THA 6 & $-\mathrm{CH}_{3}$ & 50 & 50 & 0.03 & 93.05 & 137.03 \\
\hline THA 7B & $-\mathrm{C}_{3} \mathrm{H}_{5}$ & 50 & - & 0.94 & 99.31 & 97.94 \\
\hline THA 7 & $-\mathrm{C}_{3} \mathrm{H}_{5}$ & 50 & 50 & 0.17 & 97.47 & 162.11 \\
\hline THA 8B & $\begin{array}{c}-\mathrm{C}_{8} \mathrm{H}_{17}+ \\
-\mathrm{C}_{18} \mathrm{H}_{37}\end{array}$ & 50 & - & 0.050 & 115.57 & 168.80 \\
\hline THA 8 & $\begin{array}{l}-\mathrm{C}_{8} \mathrm{H}_{17}+ \\
-\mathrm{C}_{18} \mathrm{H}_{37}\end{array}$ & 50 & 50 & 0.504 & 115.39 & 148.29 \\
\hline THA 9B & $\begin{array}{c}-\mathrm{C}_{3} \mathrm{H}_{5}+- \\
\mathrm{C}_{18} \mathrm{H}_{37}\end{array}$ & 50 & - & 0.012 & 101.79 & 166.65 \\
\hline THA 9 & $\begin{array}{c}-\mathrm{C}_{3} \mathrm{H}_{5}+- \\
\mathrm{C}_{18} \mathrm{H}_{37}\end{array}$ & 50 & 50 & 0.505 & 98.19 & 106.40 \\
\hline THA 10B & $\begin{array}{c}-\mathrm{C}_{3} \mathrm{H}_{6^{-}} \\
\mathrm{NH}_{2}+- \\
\mathrm{C}_{2} \mathrm{H}_{2}- \\
\mathrm{CF}_{3}\end{array}$ & 100 & - & 0.090 & 95.44 & 170.94 \\
\hline THA 10 & $\begin{array}{c}-\mathrm{C}_{3} \mathrm{H}_{6^{-}} \\
\mathrm{NH}_{2}+- \\
\mathrm{C}_{2} \mathrm{H}_{2-}^{-} \\
\mathrm{CF}_{3}\end{array}$ & 100 & 20 & 0.081 & 93.86 & 146.21 \\
\hline
\end{tabular}
angle, however, remains nearly unvaried at $115^{\circ}$ namely typical of superhydrophobic films $\left(>115^{\circ}\right)$.

Table 3. Roughness $\left(R_{a}\right)$, Wenzel $\left(\theta_{\mathrm{w}}\right)$ and Young $\left(\theta_{\mathrm{Y}}\right)$ contact angles for AquaSun xerogel films deposited on glass substrates

${ }^{a}$ Data expressed as mean of three replicates. Different letters indicate significant differences at $\mathrm{p}<0.05$ 
The roughness values of the coatings (listed in Table 3) are very low, in the range $0.05-0.94$ $\mu \mathrm{m}$, typical of the glass surface on which the film are deposited. Consequently, the coatings are not affected by the roughness of the substrate. Accordingly, the contact angle values are very high, in the super-hydrophobicity range $\left(\theta_{Y}\right.$ values grow up to $\left.168^{\circ}\right)$. Instead, when the xerogel is deposited on a metallic substrate (such as the $\mathrm{DH}_{3} 6$ steel coated with primer and tie-coat), the roughness increases reaching up to $9.31 \mu \mathrm{m}$ (see Table 1), an order of magnitude higher. This increase in the roughness of the substrate causes the Young's contact angle value to decrease to about $92^{\circ}$ (hydrophobicity). In general, the values of $Q_{r}$ are higher in samples containing the dopant (bismuth wolframate) than in corresponding samples without the dopant species. In particular, the THA10B and THA8B samples are those with super-hydrophobicity values around $170^{\circ}\left(168.80^{\circ}\right.$ and $170.94^{\circ}$, respectively).
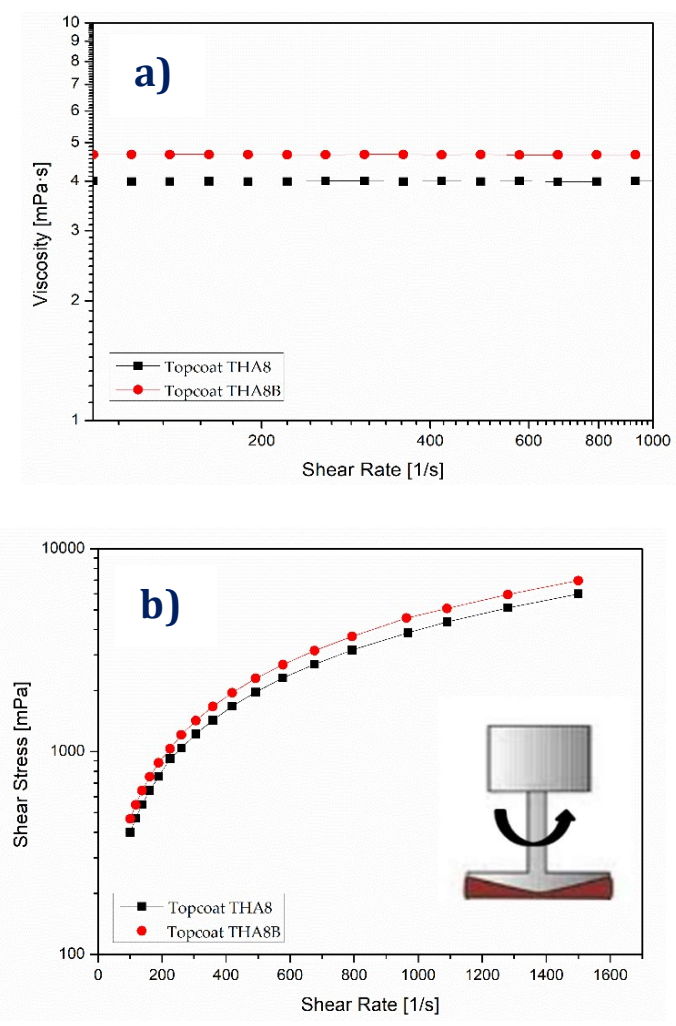

Figure 6. Viscosity (a) and flow (b) curves for THA8 and THA8B topocoats (inset: cone-plate geometry of the rotational rheometer).

Figure 6 shows evidence that the viscosity of the samples remained constant across the entire measuring range of shear rate $\left(0.01-1000 \mathrm{~s}^{-1}\right)$, in agreement to ideally viscous flow behavior. Within the whole shear rate range investigated, the topcoats THA8 and THA8B displayed ideally viscous flow behavior, returning viscosity values of $4 \mathrm{mPas}$ and $4.7 \mathrm{mPas}$, respectively. In brief, the addition of bismuth wolframate to the xerogel formulation improves the viscosity of the coating but it does not affect the viscous flow behavior. Coupled to the fact that the workability of the coating does not appreciably change, this is important in sight of forthcoming practical applications of the AquaSun coatings.

\section{CONCLUSIONS}

On path to demonstrate the practical applicability of the new antifouling/foul release AquaSun marine sol-gel coating, we report the outcomes of adhesion and ecotoxicity tests carried out on steel specimens faithfully representing the metal surface of real ships, including the topcoat layer typically applied on the ship hull prior to deposition of the 
antifouling paint. The results of Microtox tests on the first generation AquaSun sol-gel derived organosilica coatings clearly show that AquaSun is an environmentally benign and ecologically safe coating. To enhance the contact angle and make the coating superhydrophobic (contact angle $>115^{\circ}$ ), it is enough to replace MTES in the original MTES:TEOS 1:1 composition with a C8:C18 49:1 alkylsilane mixture in full agreement with their early studies on sol-gel organosilica antifouling coatings based on the foul release mechanism. ${ }^{[9,17]}$ The addition of bismuth wolframate does not appreciably alter the coating workability. Preliminary investigation of marine bacteria growth on the coated films confirms previous findings ${ }^{[12,15]}$ that the $\mathrm{AF}$ mechanism is indeed due to photocatalysis promoted by the encapsulated $\mathrm{Bi}_{2} \mathrm{WO}_{6}$.

The key outcome of this investigation, most promising in light of forthcoming practical applications of this new class of antifouling paint, is that these coatings share exceptionally high scratch resistance due to the excellent adhesion of the partly hydrolysed Si alkoxides levels to the hydroxyl groups at the surface of the epoxy-protected steel. Similar maximum values of adhesion strength (ASTM $5 \mathrm{~B}$ ) are observed only for the most resistant coatings usually deposited with expensive physical vapor deposition and chemical vapor deposition techniques. ${ }^{[20]}$ In the context of ongoing research on epoxy-, silane-, and polyurethanebased AF/FR coatings, ${ }^{[23]}$ a forthcoming techno-economic study will whether this new class of organosilica-based photocatalytic coatings, merging the foul release properties of solgel foul release coatings ${ }^{[11]}$ and the powerful visible-light photocatalytic activity of $\mathrm{Bi}_{2} \mathrm{WO}_{6}{ }^{\left[{ }^{[24]}\right]}$ is suitable for industrial production.

\section{ACKNOWLEDGMENTS}

This study is dedicated to the memory of Professor Michael R. Detty (1951-2020). This research was funded by NAVTEC (Consorzio di Ricerca per I'Innovazione tecnologica, Sicilia, Trasporti navali, commerciali e da diporto s.c.a.r.l), project "Thalassa -TecHnology and materials for safe Low consumption and low life cycle cost veSSels and crafts", grant number ARS01_00293 PON2014-2020. We thank Dr Simone Cappello, Istituto per le Risorse Biologiche e le Biotecnologie, CNR, for the Microtox eco-toxicological assay measurements.

\section{DECLARATION OF INTERESTS}

The authors declare no competing interests.

Data availability

All data reported in this study are freely available by contacting the corresponding Authors.

\section{REFERENCES}

[1] M.P. Schultz, J.A. Bendick, E.R. Holm, W.M. Hertel, Economic impact of biofouling on a $\begin{array}{lllll}\text { naval surface ship, Biofouling 2010, } & \text { 87-98. }\end{array}$ https://doi.org/10.1080/08927014.2010.542809

[2] D. Howell, B. Berhends, Consequences of antifouling coatings - The chemist's perspective in Biofouling, S. Dürr, J.C. Thomason (Ed.s), Blackwell Publishing, Oxford: 2009; pp.226-242. https://doi.org/10.1002/9781444315462.ch16

[3] D. Williams, Challenges in developing antifouling coatings, IMarEST, London, 2010.

[4] Infiniti Research, Global Antifouling Coatings Market 2021-2025, Bengaluru (India): 2021.

[5] I. Amara, W. Miled, R. Ben Slama, N. Ladhari, Antifouling processes and toxicity effects of antifouling paints on marine environment. A review, Environ. Toxicol. Pharmacol. 2018, 57, 115-130. https://doi.org/10.1016/j.etap.2017.12.001 
[6] F. Cima, R. Varello, Potential disruptive effects of copper-based antifouling paints on the biodiversity of coastal macrofouling communities, Research Square 2021, https://doi.org/10.21203/rs.3.rs-827075/v1

[7] R. Ciriminna, F.V. Bright, M. Pagliaro, Ecofriendly antifouling marine coatings, ACS Sustainable Chem. Eng. 2015, 3, 559-565. https://doi.org/10.1021/sc500845n

[8] S.K. Kyei, G. Darko, O. Akaranta, Chemistry and application of emerging ecofriendly antifouling paints: a review, J. Coat. Technol. Res. 2020, 17, 315-332. https://doi.org/10.1007/s11998-019-00294-3

[9] Y. Tang, J.A. Finlay, G.L Kowalke, A.E. Meyer, F.V Bright, M.E. Callow, J.A. Callow, D.E. Wendt, M.R. Detty, Hybrid xerogel films as novel coatings for antifouling and fouling release, Biofouling 2005, 21, 59-71. https://doi.org/10.1080/08927010500070935

[10] M.R. Detty, R. Ciriminna, F.V. Bright, M. Pagliaro, Xerogel coatings produced by the sol-gel process as anti-fouling, fouling-release surfaces: from lab bench to commercial reality, ChemNanoMat 2015, 1, 148-154. http://dx.doi.org/10.1002/cnma.201500056

[11] M.R. Detty, R. Ciriminna, F.V. Bright, M. Pagliaro, Environmentally benign sol-gel antifouling and foul-releasing coatings, Acc. Chem. Res. 2014, 47, 678-687. http://dx.doi.org/10.1021/ar400240n

[12] G. Scandura, R. Ciriminna, Y.-J. Xu, M. Pagliaro, G. Palmisano, Nanoflower-Like $\mathrm{Bi}_{2} \mathrm{WO}_{6}$ encapsulated in ORMOSIL as a novel photocatalytic antifouling and foul-release coating, Chem. Eur. J. 2016, 22, 7063-7067. http://dx.doi.org/10.1002/chem.201600831

[13] S.M. Olsen, J.B. Kristensen, B.S. Laursen, L.T. Pedersen, K. Dam-Johansen, S. Kiil, Antifouling effect of hydrogen peroxide release from enzymatic marine coatings: Exposure testing under equatorial and Mediterranean conditions, Prog. Org. Coat. 2010, 68, 248-252. http://dx.doi.org/10.1016/j.porgcoat.2010.01.003

[14] H. Elzanowska, R.G. Wolcott, D.M. Hannum, J.K. Hurst, Bactericidal properties of hydrogen peroxide and copper or iron-containing complex ions in relation to leukocyte function, Free Radic. Biol. Med. 1995, 18, 437-449. https://doi.org/10.1016/08915849(94)00150-I

[15] G. Scandura, R. Ciriminna, L. Yıldız Ozer, F. Meneguzzo, G.Palmisano, M. Pagliaro, Antifouling and photocatalytic antibacterial activity of the AquaSun coating in seawater and related media, ACS Omega 2017, 2, 7568-7575. https://doi.org/10.1021/acsomega.7b01237

[16] P.G. Falkowski, The role of phytoplankton photosynthesis in global biogeochemical cycles, Photosynth. Res. 1994, 39, 235-258. https://doi.org/10.1007/BFo0014586

[17] N. Gunari, L. H. Brewer, S.M. Bennett, A. Sokolova, N.D. Kraut, J.A. Finlay, A.E. Meyer, G.C. Walker, D.E. Wendt, M.E. Callow, J.A. Callow, F.V. Bright, M.R. Detty, The control of marine biofouling on xerogel surfaces with nanometer-scale topography, Biofouling 2011, 27, 137-149. https://doi.org/10.1080/08927014.2010.548599

[18] M. Pagliaro, R. Ciriminna, G. Palmisano, Silica-based hybrid coatings, J. Mater. Chem. 2009, 19, 3116-3126. http://dx.doi.org/10.1039/b819615j

[19] ASTM D 3359-92a, Standard Test Methods for Measuring Adhesion by Tape Test; ASTM: 1992. 
[20] J. Valli, A review of adhesion test methods for thin hard coatings, J. Vac. Sci. Technol. A 1986, 4, 3007-3012. https://doi.org/10.1116/1.573616

[21] B.T. Johnson, Microtox Acute Toxicity Test, In Small-scale Freshwater Toxicity Investigations, C. Blaise, J.F. Férard (Ed.s), Springer, Dordrecht: 2005. https://doi.org/10.1007/1-4020-3120-3_2

[22] D. M. McMaster, S. M. Bennett, Y. Tang, J. A. Finlay, G.L. Kowalke, B. Nedved, F.V. Bright, M.E. Callow, J.A. Callow, D.E. Wendt, M.G. Hadfield, M.R. Detty, Antifouling character of 'active' hybrid xerogel coatings with sequestered catalysts for the activation of hydrogen peroxide, Biofouling 2009, 25, 21-33. https://doi.org/10.1080/08927010802431298

[23] A. Pistone, C. Scolaro, A. Visco, Mechanical properties of protective coatings against marine fouling: a review, Polymers 2021, 13, 173. https://doi.org/10.3390/polym13020173

[24] N. Zhang, R. Ciriminna, M. Pagliaro, Y.-J. Xu, Nanochemistry-derived $\mathrm{Bi}_{2} \mathrm{WO}_{6}$ nanostructures: towards sustainable chemicals and fuels production induced by visible light, Chem. Soc. Rev. 2014, 43, 5276-5287. http://dx.doi.org/10.1039/c4cs00056k 